\title{
Hard X-ray Nanotomography of Catalytic Solids at Work**
}

\author{
Ines D. Gonzalez-Jimenez, Korneel Cats, Thomas Davidian, Matthijs Ruitenbeek, \\ Florian Meirer, Yijin Liu, Johanna Nelson, Joy C. Andrews, Piero Pianetta, \\ Frank M. F. de Groot, and Bert M. Weckhuysen*
}

\begin{abstract}
Advances in microscopy such as a spatial resolution in the nanometer range combined with higher chemical and morphological sensitivities have improved the imaging of functional materials. ${ }^{[1,2]}$ Optical and electron microscopy techniques are commonly employed; however, they may not always be applicable for nondestructive imaging if the sample is either optically opaque or too thick to be penetrated by electrons. ${ }^{[3]}$ On the other hand, X-rays offer superior imaging resolution compared to, for example, visible-light methods because of their short wavelength and their intrinsic penetration power, which allows studying thick materials. Scanning transmission X-ray microscopy (STXM) in the soft X-ray energy region (200-2000 eV) has been used extensively for biological imaging and has been recently also introduced in the field of materials chemistry, including heterogeneous catalysis. $^{[4-7]}$ STXM combines a high spatial resolution of about $15 \mathrm{~nm}$ with chemical speciation by X-ray absorption spectroscopy using focused soft X-ray light as a probe. The sample thickness for soft X-rays must ideally be in the (sub)micron range but the gap of imaging larger particles at higher pressures and temperatures remains an important drawback. Full-field transmission hard X-ray microscopy (TXM) appears to be an excellent method to counter the current
\end{abstract}

[*] Dr. I. D. Gonzalez-Jimenez, K. Cats, Prof. Dr. F. M. F. de Groot, Prof. Dr. B. M. Weckhuysen

Inorganic Chemistry and Catalysis

Debye Institute for Nanomaterials Science

Utrecht University

Universiteitslaan 99, 3584 CG Utrecht (The Netherlands)

E-mail: b.m.weckhuysen@uu.nl

Dr. T. Davidian, Dr. M. Ruitenbeek

Dow Benelux B.V.

P.O. Box 48, 4530 AA, Terneuzen (The Netherlands)

Dr. F. Meirer

Fondazione Bruno Kessler

Via Sommarive 18, 38050 Povo (Italy)

Dr. Y. Liu, Dr. J. Nelson, Prof. Dr. J. C. Andrews, Prof. Dr. P. Pianetta

Stanford Synchrotron Light Source

SLAC National Accelerator Laboratory

Menlo Park, CA 94025 (USA)

[***] The authors acknowledge financial support from The Dow Chemical Company. The Stanford Synchrotron Radiation Lightsource (SSRL) is supported by the US Department of Energy, Office of Basic Energy Sciences. We wish to thank to A. van der Eerden (Utrecht University) for his help with the design of the reactor cell. We further acknowledge P. Williams and T. Kao (SSRL) for their help during the data processing and R. Marks (SSRL) for the setting up of the gas flow system.

upporting information for this article is available on the WWW under http://dx.doi.org/10.1002/anie.201204930. limitations in view of its potential to image the nanoscale features of thick objects because of a high penetration power ${ }^{[8]}$ Thanks to the advances in X-ray optics, synchrotron-radiation-based transmission hard $\mathrm{X}$-ray microscopes have already achieved a resolution of $30-50 \mathrm{~nm}$ from an energy range of $4000-14000 \mathrm{eV}^{[9]}$ The advantage of TXM is the possibility of working at higher pressures and reaction temperatures and of implementing 3D imaging of larger catalyst particles (10-60 microns). ${ }^{[10,11]}$ In addition, collecting a stack of images at different energies across the absorption edge makes it possible to obtain X-ray absorption spectra, even under in situ conditions. X-ray absorption near-edge spectroscopy (XANES) provides unique information on the oxidation state and local environment of the absorber element in complex multi-component materials and thus provides crucial information on the nanoscale structure of heterogeneous catalysts. Here, we show that TXM combined with a specially designed in situ reactor makes it possible to investigate the dynamic changes in morphology, porosity, and chemical composition of a $20 \mu \mathrm{m}$ catalyst particle at 10-30 bar and up to $600{ }^{\circ} \mathrm{C}$ in a reactant stream with a spatial resolution of $30 \mathrm{~nm}$.

The combination of chemical information with high spatial resolution is even more valuable when the system under study has a marked dynamic character in the catalytically active phases, as is the case for Fe-based catalysts for Fischer-Tropsch-to-Olefins synthesis ${ }^{[12]}$ (denoted as FTO). The active sites of FTO catalysts are situated on nanoparticles and the addition of promoters can improve the catalytic activity and affect the selectivity towards light olefins. Studying these Fe nanoparticles in situ allows the elucidation of the active phases and their influence on the catalyst performance. Therefore, we aim to investigate this industrially important catalytic system using in situ TXM to gain fundamental insight in their active phase and to relate phase distribution changes to a specific catalytic performance.

The TXM reactor has been designed to allow treatments of catalytic solids at $10-30$ bar and up to $600^{\circ} \mathrm{C}$ under gas flow (see Figure S1 in the Supporting Information). The catalyst is loaded into a quartz capillary $(100 \mu \mathrm{m}$ in diameter and $10 \mu \mathrm{m}$ of wall thickness). This capillary is placed on an adaptor, which is mounted on the sample stage with $x, y, z$, and $\theta$ motions and allows a 3D tomography study. The capillary is heated using a heater gun controlling the air flow to avoid undesired vibrations in the capillary. Because of the small size of the capillary, the position of the thermocouple, and the design of our reactor system an isothermal sample heating can be assumed. 
The material under study is the Ruhrchemie catalyst, selected as an important model system, ${ }^{[13]}$ which has been applied in the Fischer-Tropsch industry. This catalyst consists of a bulk iron oxide promoted with titanium, zinc, and potassium oxides and has the following relative chemical composition on a weight percentage basis: $70 \mathrm{Fe}_{2} \mathrm{O}_{3} / 20 \mathrm{TiO}_{2} /$ $6 \mathrm{ZnO} / 4 \mathrm{~K}_{2} \mathrm{O}$. Tomographic images acquired above and below the absorption edge of $\mathrm{Fe}$ and $\mathrm{Zn}$ facilitates the determination of the elemental distribution at the nanoscale. ${ }^{[14]}$ In other words, it is possible to locate the main elements and map the positions of the $\mathrm{Zn}$ promoter versus $\mathrm{Fe}$-active sites in the catalyst particle. In addition, it is also possible to study the active Fe phase chemically by following the Fe-K edge in situ with 2D TXM XANES imaging during the different treatments. The working surface in FTO synthesis consists of a complex mixture of different iron carbides $\left(\xi-\mathrm{Fe}_{2} \mathrm{C} / \xi^{\prime}-\mathrm{Fe}_{2.2} \mathrm{C}\right.$, $\mathrm{Fe}_{7} \mathrm{C}_{3}, \chi-\mathrm{Fe}_{5} \mathrm{C}_{2}$, and $\left.\theta-\mathrm{Fe}_{3} \mathrm{C}\right)$, iron oxide $\left(\mathrm{Fe}_{3} \mathrm{O}_{4}\right)$, and metallic iron $(\alpha-\mathrm{Fe}) \cdot{ }^{[15,16]}$ In our experiment, the catalyst material is imaged under working conditions during the FTO reaction at $350^{\circ} \mathrm{C}$ and 10 bar in synthesis gas $\left(\mathrm{H}_{2} / \mathrm{CO}=1\right)$. During this treatment we can study the reduction degree and its distribution by monitoring the $\mathrm{Fe}$ K-edge because the Fe species are expected to change in the catalyst material with increasing time on stream as different $\mathrm{Fe}$ species are gradually formed. The XANES spectra acquired as images of energy stacks can be fitted by using a least-squares method to obtain the relative abundance of the different Fe species present in the catalyst sample (see Figure S1 in the Supporting Information). ${ }^{[10]}$

To study the distribution of all components and the porosity of the catalyst, 3D nanotomographic reconstruction of an individual FTO catalyst particle was performed (see Movie S1 in the Supporting Information and Figure 1). The Fe and $\mathrm{Zn}$ distributions are reconstructed as a difference in tomographic data taken above and below the Fe K-edge and $\mathrm{Zn} \mathrm{K}$-edge, respectively. The potassium Kedge is out of the energy range of the beamline and the X-rays at the titanium K-edge have a poor penetration power through the 20 microns thick quartz in the capillary walls of the reactor. For that reason, the combined distribution of $\mathrm{K}$ and $\mathrm{Ti}$ is calculated from the difference between the total nanoto-
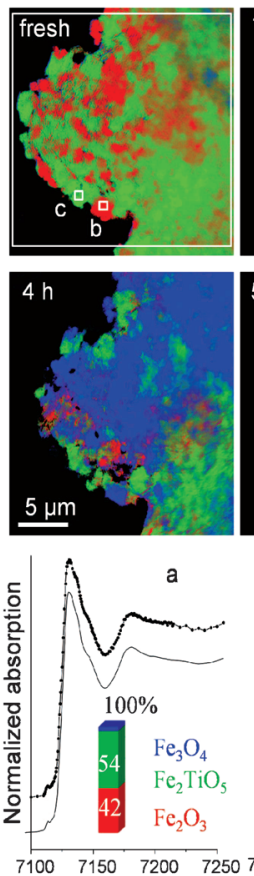

E/ eV

$E / \mathrm{eV}$
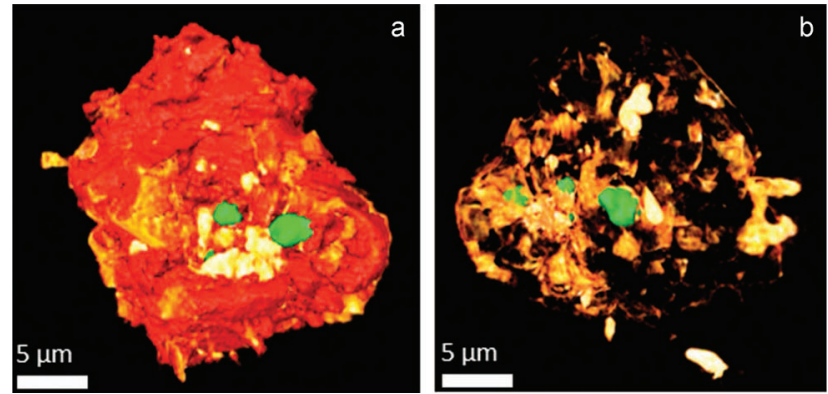

Figure 1. a, b) Snapshots of the $\mathrm{X}$-ray nanotomography video of an individual fresh FTO catalyst particle, $\mathrm{Fe}$ in red for the species $\mathrm{Fe}_{2} \mathrm{O}_{3}$, $\mathrm{Fe}_{3} \mathrm{O}_{4}$, and $\mathrm{Fe}_{2} \mathrm{TiO}_{5}, \mathrm{Zn}$ in green for $\mathrm{ZnO}$, and $\mathrm{Ti}+\mathrm{K}$ in white/yellow/ orange for $\mathrm{TiO}_{2}$ and $\mathrm{K}_{2} \mathrm{O}$ (white used for the highest concentration).

mography and the $\mathrm{Fe}$ and $\mathrm{Zn}$ components (the presence of these elements within the particle was confirmed by fluorescence prior to tomography). We note that the $\mathrm{Zn}$ particles are mainly associated with $\mathrm{Ti}$ in the catalyst particle rather than with $\mathrm{Fe}$ (Figure $1 \mathrm{a}$ and $\mathrm{b}$ ), which is not in line with the assumed role of $\mathrm{ZnO}$, being only a structural promoter. ${ }^{[17]}$ This result could explain why the positive effect is only noticed when a certain loading of the promoter relative to the amount of $\mathrm{TiO}_{2}$ present is used in the catalyst formulation.

Before performing in situ TXM experiments, we have analyzed the fresh FTO catalyst particle at room temperature
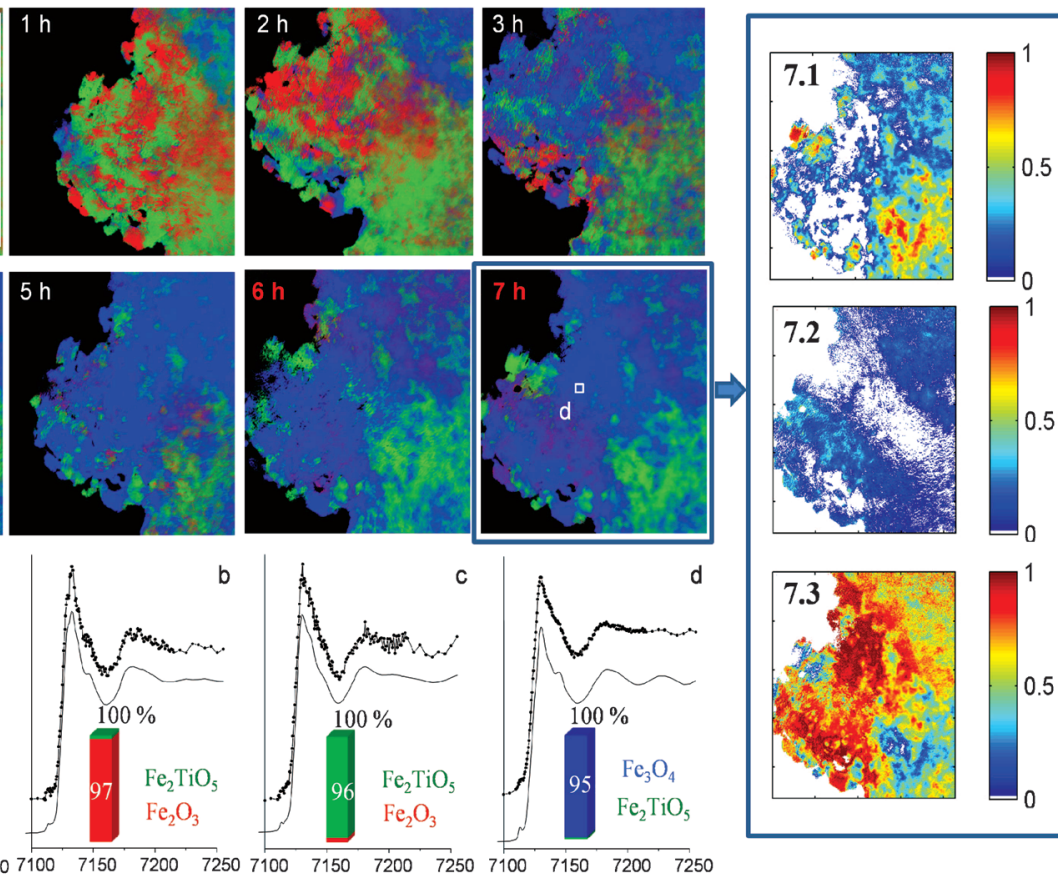

$E / \mathrm{eV}$

$E / \mathrm{eV}$

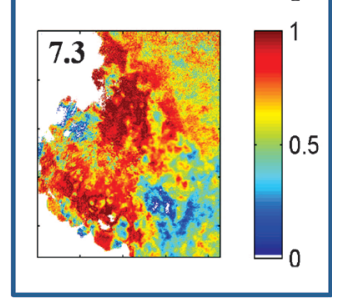

Figure 2. $2 \mathrm{D}$ chemical composite maps showing the spatial distribution of different iron species over a $21 \times 21 \mu \mathrm{m}^{2}$ particle in $\mathrm{He}$ and after $7 \mathrm{~h}$ of reaction $\left(10 \mathrm{bar}, \mathrm{H}_{2} / \mathrm{CO}=1\right.$ and $350^{\circ} \mathrm{C}$ ) as a function of the time on stream; green for $\mathrm{Fe}_{2} \mathrm{TiO}_{5}$, red for $\mathrm{Fe}_{2} \mathrm{O}_{3}$, and blue for $\mathrm{Fe}_{3} \mathrm{O}_{4}$. For the maps after $6 \mathrm{~h}$ and $7 \mathrm{~h}$ under reaction conditions: green for $\mathrm{Fe}_{2} \mathrm{TiO}_{5}$, red for $\mathrm{FeC}_{x}$, and blue for $\mathrm{Fe}_{3} \mathrm{O}_{4}$. a) Fe K-edge bulk XANES spectra of the whole particle, b-d) Fe K-edge spectra on a $28 \times 28 \mathrm{~nm}^{2}$ single pixel of three different regions. Experimental data is noted by $(\bullet)$ and $(-)$ indicates fitted data, respectively. Phase map distributions of $\mathrm{Fe}_{2} \mathrm{TiO}_{5}(7.1), \mathrm{FeC}_{x}(7.2)$, and $\mathrm{Fe}_{3} \mathrm{O}_{4}$ (7.3) over the catalyst particle after $7 \mathrm{~h}$ of time on stream. 
in a $\mathrm{He}$ atmosphere by recording images at the $\mathrm{Fe} \mathrm{K}$-edge. Figure 2 shows the 2D chemical maps of the FTO catalyst particle under study, obtained from a linear combination least-squares fit of selected reference spectra to the X-ray absorption near-edge spectrum acquired at every pixel. The experimental $\mathrm{Fe} \mathrm{K}$-edge spectrum of the fresh sample was fitted to contributions of $\mathrm{Fe}_{2} \mathrm{O}_{3}, \mathrm{Fe}_{2} \mathrm{TiO}_{5}$, and $\mathrm{Fe}_{3} \mathrm{O}_{4}$ reference spectra (see Figure S2 in the Supporting Information) at every $30 \times 30 \mathrm{~nm}^{2}$ pixel, according to the method described by Meirer et al. ${ }^{[10]}$ The $\mathrm{Fe}_{2} \mathrm{TiO}_{5}$, pseudo-brookite, is formed by reaction of $\mathrm{Fe}_{2} \mathrm{O}_{3}$ and $\mathrm{TiO}_{2}$ as a result of the high calcination temperature of the preparation procedure of the catalyst. ${ }^{[18,19]}$

The presence of the mentioned Fe oxides was confirmed by the XRD pattern obtained from the fresh catalyst material (see Figure S3 in the Supporting Information). Additionally, we have used principal component analysis (PCA) to identify spectral features, originating from different chemical species, to establish the number of species required to achieve an excellent fit quality of the spectra. ${ }^{[20-22]}$ In this way, we identified by PCA three major iron components; that is, $\mathrm{Fe}_{2} \mathrm{O}_{3}, \mathrm{Fe}_{2} \mathrm{TiO}_{5}$, and $\mathrm{Fe}_{3} \mathrm{O}_{4}$. The XANES spectrum obtained for the bulk particle (Figure $2 \mathrm{a}$ ) in its fresh state indicates that the iron phase is mainly present in the trivalent oxidized phase $\left(\mathrm{Fe}_{2} \mathrm{O}_{3}\right.$ and $\left.\mathrm{Fe}_{2} \mathrm{TiO}_{5}\right)$, showing the absorption peak at $7123 \mathrm{eV}$ and the pre-edge feature at $7114 \mathrm{eV}$ originating from the $1 \mathrm{~s}$-to-3d transition. The quantitative analysis of the bulk spectra indicates that $\alpha-\mathrm{Fe}_{2} \mathrm{O}_{3}$ contributes with $42 \%$ to the spectrum, while $\mathrm{Fe}_{2} \mathrm{TiO}_{5}$ contributes with almost $54 \%$, the remaining fraction being $\mathrm{Fe}_{3} \mathrm{O}_{4}$ (Figure $2 \mathrm{a}$ ).

Figure $2 \mathrm{~b}$ and $\mathrm{c}$ shows the single pixel XANES spectra obtained from pixels selected within the regions where the two main components are present in the fresh FTO catalyst particle. The linear combination of both spectra results in $97 \% \mathrm{Fe}_{2} \mathrm{O}_{3}, 3 \% \mathrm{Fe}_{2} \mathrm{TiO}_{5}, 4 \% \mathrm{Fe}_{2} \mathrm{O}_{3}$, and $96 \% \mathrm{Fe}_{2} \mathrm{TiO}_{5}$, in regions $\mathrm{b}$ and $\mathrm{c}$, respectively. Note that the experimental spectrum obtained on a single pixel allows a high-quality fitting of the standards (average R-squared and R-factor values of 0.26 and 0.0015 , respectively).

The system was then pressurized with $\mathrm{He}$ and heated up to relevant FTO conditions $\left(350^{\circ} \mathrm{C}\right.$ and 10 bar). After such conditions were reached the He flow was switched to a syngas stream with a $\mathrm{H}_{2} / \mathrm{CO}$ ratio of $1: 1$. The evolution of Fe species at different times on stream is given in Figure 2 (see also Movie S2 in the Supporting Information). The Fe K-edge spectra of the pixel in region (d) of the particle under FTO conditions is shown in Figure $2 \mathrm{~d}$, being the quantitative analysis by a linear combination fit of $95 \% \mathrm{Fe}_{3} \mathrm{O}_{4}$ and $5 \%$ $\mathrm{Fe}_{2} \mathrm{TiO}_{5}$. The presence of $\mathrm{Fe}$ and $\mathrm{FeO}$ in the linear combination fits did not improve the spectral fits in any of the images suggesting that both species are not stable intermediate phases during reduction and carburization of $\mathrm{Fe}_{2} \mathrm{O}_{3}$, in agreement with literature. ${ }^{[23]}$ We note that during reduction $\mathrm{Fe}_{2} \mathrm{O}_{3}$ is first reduced to $\mathrm{Fe}_{3} \mathrm{O}_{4}$ before the reduction of $\mathrm{Fe}_{2} \mathrm{TiO}_{5}$, which is still present after $7 \mathrm{~h}$ of reaction. It is clear that after $7 \mathrm{~h}$ of time on stream (Figure 3 ) the catalyst is almost fully transformed into the reduced iron species, that is, $\mathrm{Fe}_{3} \mathrm{O}_{4}$ and $\mathrm{FeC}_{x}$. In the case of the iron carbides, we have used the $\theta-\mathrm{Fe}_{3} \mathrm{C}$ reference (considered to be the most stable carbide phase) to estimate the total amount of iron carbides,

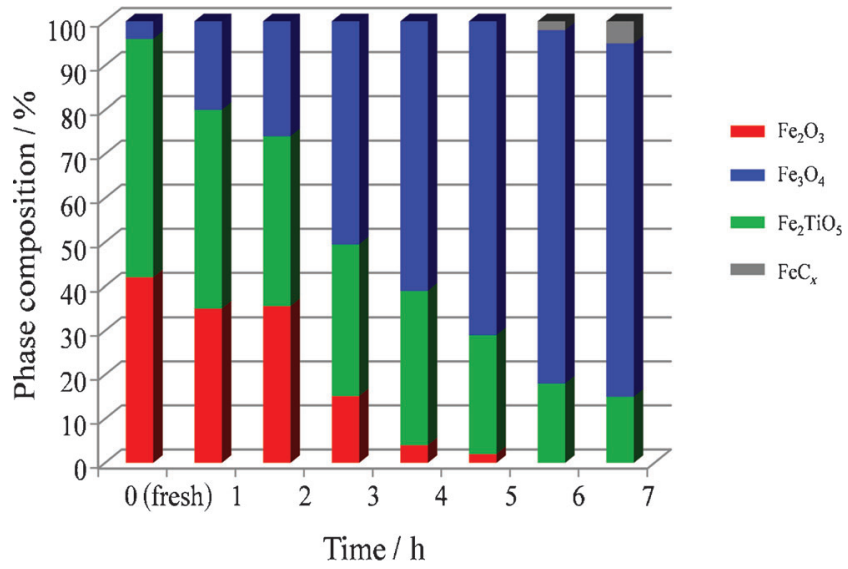

Figure 3. Relative contribution of Fe species resulting from a linear combination fit of the bulk XANES spectra of reference compounds as a function of the time on stream corresponding with the images shown in Figure 2.

because the different types of iron carbides have similar nearedge structures. ${ }^{[24,25]}$ The quality of the fit is clearly improved when the iron carbide standard is included in the case of the last 2D chemical maps. As it can be seen in Figure 2 (7.2) the iron carbide phase is dispersed in very small clusters where the $\mathrm{Fe}_{2} \mathrm{O}_{3}$ was originally present in the fresh catalyst particle. Furthermore, the presence of iron carbide is confirmed after $5 \mathrm{~h}$ of time on stream, which does not implicate its absence during the previous hours, but the amount and particle size of the carbide is assumed to be too small to be detected accurately.

To establish a relationship between the spatiotemporal changes in the iron phases, as measured by TXM, and the catalytic performance of the catalyst material we have conducted catalytic testing experiments under similar conditions as those employed for the TXM measurements. It is important to stress that these conditions are demanding for the catalyst material as high space velocities have been used. The catalytic performance results are summarized in Figure $4 \mathrm{a}$ and $\mathrm{b}$ as well as in Figure S4 of the Supporting Information. It was found that after $7 \mathrm{~h}$ on stream the $\mathrm{CO}$ conversion reached a value of $7.1 \times 10^{-6} \mathrm{~mol} \mathrm{CO} \mathrm{g}^{-1} \mathrm{Fe} \mathrm{s}^{-1}$, while the selectivity towards $\mathrm{C}_{2}-\mathrm{C}_{4}$ olefins ranges from $16 \%$, $7 \%$, and $3 \%$ for propene, ethylene and butane, respectively. Comparison between Figure $4 \mathrm{a}$ and $\mathrm{b}$ leads to the conclusion that the maximum olefin production matches with the time needed to reach the maximum $\mathrm{CO}$ conversion, which is after $2 \mathrm{~h}$ on stream. In other words, the most selective FTO catalyst material is formed at the same time, which corresponds with a catalyst material composed of a growing amount of $\mathrm{Fe}_{3} \mathrm{O}_{4}$, next to $\mathrm{Fe}_{2} \mathrm{O}_{3}$ and $\mathrm{Fe}_{2} \mathrm{TiO}_{5}$. This observation is illustrated in Figure 2.

Interestingly, in this material we can find by using separate in situ X-ray diffraction (XRD) measurements the formation of an iron carbide phase (Figure S5 in the Supporting Information). Recently, detailed physicochemical studies ${ }^{[26]}$ have shown that the surface areas of $\mathrm{Fe}_{3} \mathrm{O}_{4}$ and $\mathrm{FeC}_{x}$ control the conversion rates, irrespective of the residual iron oxides, and those catalysts with high yields towards olefins have 
a)

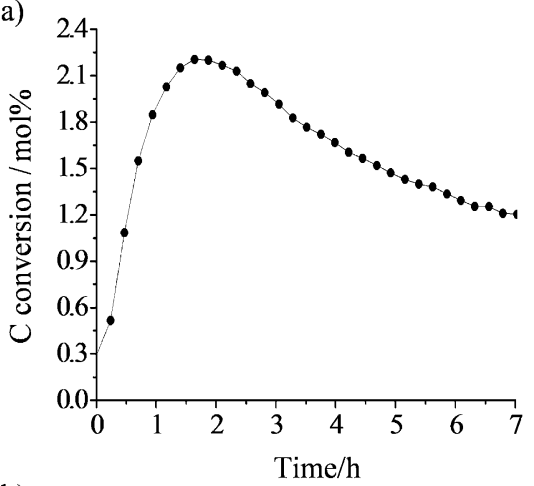

b)

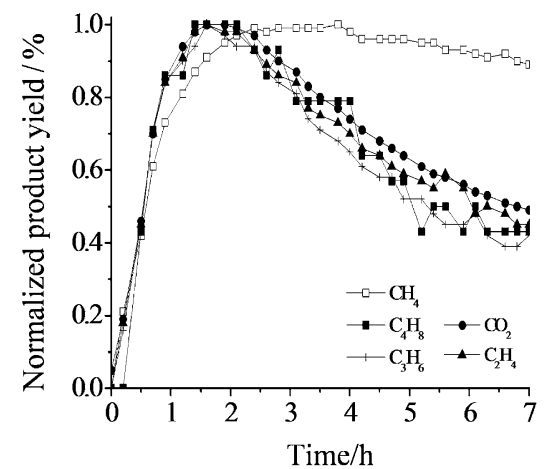

Figure 4. Catalytic activity data of the FTO catalyst material under study at 10 bar, $350^{\circ} \mathrm{C}$, and $\mathrm{H}_{2} / \mathrm{CO}=1$. a) Carbon conversion as a function of the time on stream and b) normalized product yield, specifically the selectivity towards propene, ethylene, butene, carbon dioxide, and methane.

better reduction and carburization properties. The low carburization degree of our catalyst because of the overall presence of $\mathrm{Fe}_{2} \mathrm{TiO}_{5}$, could explain the lower FTO activity. It is very likely that $\mathrm{FeC}_{x}$ is formed as soon as $\mathrm{Fe}_{3} \mathrm{O}_{4}$ is in contact with syngas, but in our experiments the $\mathrm{FeC}_{x}$ crystallites could be too small to be readily detected by TXM, although already visible in the bulk XRD measurements. With increasing time on stream the $\mathrm{FeC}_{x}$ crystallites become bigger and/or increase in their amount, which goes hand in hand with an increasing selectivity towards methane as well as a decreasing CO conversion. Boudart and co-workers ${ }^{[27]}$ already found a relationship between the iron particle size and its selectivity, indicating that large iron particles were more active for methane production showing lower selectivity for $\mathrm{C}_{2+}$. Our TXM and catalytic performance data confirm these observations by Boudart and co-workers, which were based on $\mathrm{CO}$ titration experiments of pretreated Fe-based FTO catalysts. It is generally assumed that water (a product of the FischerTropsch reaction) has a strong inhibiting influence on the reaction rate. ${ }^{[28,29]}$ In the case of a higher concentration of water on the surface of the catalyst and/or a slight decrease in temperature (reported for $\left.20-40^{\circ} \mathrm{C}\right)^{[30]}$ because of possible temperature deviation induced by the gun heater, the further reduction of magnetite to form $\mathrm{FeC}_{x}$ would not be favored. This could also explain the high amount of $\mathrm{Fe}_{3} \mathrm{O}_{4}$ and the low FTO activity observed.
We have demonstrated that full-field hard X-ray transmission microscopy provides unprecedented possibilities for in situ 3D characterization of an individual catalyst particle with nanometer spatial resolution and elemental sensitivity under realistic reaction conditions; that is, high temperatures and pressures. This innovative approach allows unravelling the complex interplay of different chemical components and their related spatial distribution, as shown here for a Ruhrchemie Fe-based FTO catalyst. This approach is not only relevant for scientists working in the field of heterogeneous catalysis, but also for those active in other fields, such as environmental science, energy storage and geology.

\section{Experimental Section}

The $\mathrm{Fe}_{2} \mathrm{O}_{3} / \mathrm{TiO}_{2} / \mathrm{ZnO} / \mathrm{K}_{2} \mathrm{O}$ catalyst material was prepared by mixing the corresponding oxides. The resulting brown material was pelletized (about $5 \mathrm{kN} \mathrm{m}^{-2}$ ), crushed, and sieved to collect the desired particle size before it was loaded into the quartz capillary. TXM experiments were performed on the Xradia nano-XCT full-field transmission Xray microscope (TXM) at beamline 6-2 (BL6-2c) of the Stanford Synchrotron Radiation Facility, USA. The TXM, developed at the 54 pole wiggler beamline, is based on zone plate optics using absorption contrast over a wide energy range from $5-14 \mathrm{keV}$ and Zernike contrast at $8 \mathrm{keV}$. A Vortex detector is employed to collect the fluorescence signal and subsequently to determine the elements that are present in the sample prior to TXM imaging. The TXM makes use of a Fresnel zone plate with $200 \mu \mathrm{m}$ in diameter and $30 \mathrm{~nm}$ for the outermost zone width to achieve a magnification factor of around 50 depending on the configuration of the incident X-ray energy. A $2048 \times$ 2048 pixels Peltier-cooled charge-coupled device (CCD) is used to collect the projection images with spatial resolution as good as about $30 \mathrm{~nm}$ over a field of view of about $32 \times 32 \mu \mathrm{m}^{2}$ as confirmed using a Siemens calibration standard. It is useful to note that the energy of the incident $\mathrm{X}$-rays is tuned over a considerably wide range to perform elemental/chemical sensitive TXM imaging. As a result, the zone plate position needs to be adjusted accordingly. The data collected was analyzed using the TXM_Wizard BL6-2 package software, which includes the TXM-XANESWizard. This program has been used for the magnification correction, image alignment, determination of edge energy, and for the least-squares linear combination fitting. Details on the software can be found at: http:// sourceforge.net/projects/txm-wizard.

Received: June 23, 2012

Revised: September 19, 2012

Published online: October 22, 2012

Keywords: Fischer-Tropsch catalysis - heterogeneous catalysis . in situ spectroscopy - transmission X-ray microscopy . X-ray absorption spectroscopy

[1] J.-D. Grunwaldt, C. G. Schroer, Chem. Soc. Rev. 2010, 39, 4741.

[2] B. Kaulich, P. Thibault, A. Gianoncelli, M. Kiskinova, J. Phys. Condens. Matter 2011, 23, $083002-083024$.

[3] J. M. Thomas, J. Hernandez-Garrido, Angew. Chem. 2009, 121, 3962-3965; Angew. Chem. Int. Ed. 2009, 48, 3904-3907.

[4] E. De Smit, I. Swart, J. F. Creemer, G. H. Hoveling, M. K. Gilles, T. Tyliszczak, P. J. Kooyman, H. W. Zandbergen, C. Morin, B. M. Weckhuysen, F. M. F. de Groot, Nature 2008, 456, 222-225.

[5] I. N. Koprinarov, A. P. Hitchcock, C. T. McCrory, R. F. Childs, J. Phys. Chem. B 2002, 106, 5358-5364. 


\section{Angewandte}

[6] G. A. Johansson, T. Tyliszczak, G. E. Mitchell, M. H. Keefe, A. P. Hitchcock, J. Synchrotron Radiat. 2007, 14, 395-402.

[7] L. R. Aramburo, E. de Smit, B. Arstad, M. M. van Schooneveld, L. Sommer, A. Juhin, T. Yokosawa, H. W. Zandbergen, U. Olsbye, F. M. F. de Groot, B. M. Weckhuysen, Angew. Chem. 2012, 124, 3676-3679; Angew. Chem. Int. Ed. 2012, 51, $3616-$ 3619.

[8] H. H. Liu, S. Schmidt, H. F. Poulsen, A. Godfrey, Z. Q. Liu, J. A. Sharon, X. Huang, Science 2011, 332, 833-834.

[9] J. C. Andrews, S. Brennan, Y. Liu, P. Pianetta, E. A. C. Almeida, M. C. H. Van Der Meulen, Z. Wu, Z. Mester, L. Ouerdane, J. Gelb, M. Feser, J. Rudati, A. Tkachuk, W. Yun, J. Phys. Conf. Ser. 2009, 186.

[10] F. Meirer, J. Cabana, Y. Liu, A. Mehta, J. C. Andrews, P. Pianetta, J. Synchrotron Radiat. 2011, 18, 773 - 781.

[11] G. J. Nelson, W. M. Harris, J. R. Izzo Jr., K. N. Grew, W. K. S. Chiu, Y. S. Chu, J. Yi, J. C. Andrews, Y. Liu, P. Pianetta, Appl. Phys. Lett. 2011, 98, 173109

[12] M. Janardanarao, Ind. Eng. Chem. Res. 1990, 29, 1735-1753.

[13] B. Bussemeier, C. Frohning, B. Cornils, Hydrocarbon Process. 1976, 55, $105-112$.

[14] Y. Liu, F. Meirer, J. Wang, G. Requena, P. Williams, J. Nelson, A. Mehta, J. C. Andrews, P. Pianetta, Anal. Bioanal. Chem. 2012, 404, 1297-1301.

[15] J. W. Niemantsverdriet, A. M. Vanderkraan, J. Catal. 1981, 72, $385-388$.

[16] E. De Smit, B. M. Weckhuysen, Chem. Soc. Rev. 2008, 37, 2758 2781
[17] S. Li, A. Li, S. Krishnamoorthy, E. Iglesia, Catal. Lett. 2001, 77, 197-205.

[18] F. C. Gennari, J. J. A. Gamboa, D. M. Pasquevich, J. Mater. Sci. Lett. 1998, 17, 697-700.

[19] A. Navrotsky, Am. Mineral. 1975, 60, 249-256.

[20] M. Lerotic, C. Jacobsen, T. Schafer, S. Vogt, Ultramicroscopy 2004, 100, 35-57.

[21] M. Fernandez-Garcia, Catal. Rev. Sci. Eng. 2002, 44, 59-121.

[22] A. Piovano, G. Agostini, A. I. Frenkel, T. Bertier, C. Prestipino, M. Ceretti, W. Paulus, C. Lamberti, J. Phys. Chem. C 2011, 115, $1311-1322$.

[23] S. Z. Li, G. D. Meitzner, E. Iglesia, J. Phys. Chem. B 2001, 105, $5743-5750$.

[24] N. S. Kopelev, V. Chechersky, A. Nath, Z. L. Wang, E. Kuzmann, B. S. Zhang, G. H. Via, Chem. Mater. 1995, 7, 1419-1421.

[25] S. Takenaka, M. Serizawa, K. Otsuka, J. Catal. 2004, 222, $520-$ 531.

[26] S. Z. Li, W. P. Ding, G. D. Meitzner, E. Iglesia, J. Phys. Chem. B 2002, 106, 85-91.

[27] M. A. McDonald, D. A. Storm, M. Boudart, J. Catal. 1986, 102, $386-400$.

[28] M. E. Dry, L. J. Boshoff, T. Shingles, J. Catal. 1972, 25, 99-104.

[29] P. C. Thune, P. Moodley, F. Scheijen, H. Frediksson, R. Lancee, J. Kropf, J. Miller, J. W. Niemantsverdriet, J. Phys. Chem. C 2010, 140, $98-104$.

[30] V. R. R. Pendyala, G. Jacobs, J. C. Mohandas, M. Luo, H. H. Hamdeh, Y. Ji, M. C. Ribeiro, B. H. Davis, Catal. Lett. 2010, 140, $98-105$. 